\title{
MULTIPARENTALIDADE: A INTRINCADA RELAÇÃO ENTRE A REALIDADE FAMILIAR E O ENUNCIADO NORMATIVO, ANALISADA À LUZ DO DIREITO POSTO E DO DIREITO PRESSUPOSTO
}

\author{
MULTIPARENTING: THE INTRINCATE RELATIONSHIP BETWEEN A FAMILY REALITY \\ AND LAW: ANALYZED ACCORDING THE RIGHT AND RIGHT ASSUMPTION
}

\author{
Melrian Ferreira da Silva Simões * \\ Valéria Aurelina da Silva Leite ${ }^{* *}$ \\ Iara Rodrigues de Toledo***
}

Data de recebimento: 02/03/2015

Data da aprovação: 10/06/2015

\section{RESUMO}

O presente trabalho tem como objeto analisar a multiparentalidade e a ausência de previsão normativa sobre o tema, como entrave ao reconhecimento da filiação socioafetiva. Em um primeiro plano, visa demonstrar como era o modelo tradicional

* Mestranda em Teoria Geral do Direito e do Estado no "Centro Universitário Eurípides de Marilia - UNIVEM" (2014), sendo bolsista CAPES. Especialista em Direito Civil e Direito

Processual Civil pelo "Centro Universitário Eurípides de Marilia - Univem", Participante do Grupo de Pesquisa em Ética do Afeto (GPEA) e do Grupo de Estudos, Pesquisas, Integração e

Práticas Integrativas (GEP) ambos da instituição "Centro Universitário Eurípides de Marilia - UNIVEM". Advogada. E-mail: melriansimoes@gmail.com

** Mestranda em Teoria Geral do Direito e do Estado no "Centro Universitário Eurípides de

Marilia - UNIVEM" (2014). Bacharel em Direito e em Administração pela Faculdade de Ciências Gerais de Dracena; especialista em Liderança pela Faculdade de Ciências Gerenciais de Dracena. Participante do Grupo de Pesquisa em Ética do Afeto (GPEA). Estado no "Centro

Universitário Eurípides de Marilia - UNIVEM”. E-mail: valeria_aurelina@hotmail.com

*** Docente do Programa de Mestrado na área de Direito do Centro Universitário Eurípides - UNIVEM - Marilia - SP; líder do Grupo de Pesquisa A Ética do Afeto. Mestre e

Doutora em Direito das Relações Sociais pela Pontifícia Universidade Católica de São Paulo - PUC/SP. Procuradora do Estado de São Paulo aposentada. Advogada. Avaliadora dos

Cursos de Graduação em Direito INEP/MEC. E-mail: iarardetoledo@uol.com.br 
de família e como as mudanças sociais, econômicas, políticas vieram a influenciar e colaborar com o surgimento de novos arranjos familiares, entre eles, o da família recomposta, cujas relações afetivas estabelecidas entre padrastos e enteados surgem e desenvolvem-se relação parental socioafetiva que, longe de excluir a parentalidade biológica, vem a dignificar o indivíduo promovendo-o em uma nova família. Os ensinos e os apontamentos sobre o Direito Posto e o Direito Pressuposto servirão como instrumento de argumentação favorável ao reconhecimento da multiparentalidade como realidade fática que deve ser reconhecida judicial e legislativamente. A abordagem é qualitativa e quantitativa e os objetivos são exploratórios e descritivos. Em sede de conclusão, entende-se que o reconhecimento da multiparentalidade é indispensável como forma de atenção e respeito a princípios constitucionais como o da dignidade da pessoa humana, da igualdade e, como valorização do afeto como elemento essencial nas relações familiares.

\title{
PALAVRAS-CHAVE
}

Família; Famílias Recompostas; Multiparentalidade; Direito

\begin{abstract}
This work has as object of analysis the multiparenting and the absence of legislative provisions on the subject, as an obstacle to the recognition of socio-affective affiliation. Visa on a foreground, demonstrate how was the traditional family model and how social, economic, political, were to influence and collaborate with the emergence of new family arrangements, including the recomposed family, where through the affective relations established between stepparents and stepchildren arises and develops socio-affective parental relationship, which far from excluding the biological parenthood comes to dignify the individual promoting it in a new family. The teachings and notes on the Law Office and the Law Assumption, serve as argument instrument favorable to the recognition of multiparenting as objective reality that must be recognized judicial and legislatively. The approach is qualitative and quantitative and objectives are exploratory and descriptive. When it's completed, it is understood that the recognition of multiparenting is essential as a means of attention and respect the constitutional principles such as human dignity, equality and, as recovery of affection as an essential element in family relationships.
\end{abstract}

\section{KEYWORDS}

Family; Recomposed Family; Multiparenting; Right 


\section{INTRODUÇÃO}

A história da humanidade é permeada por mudanças, sejam elas comportamentais, sociais, econômicas, políticas, religiosas ou outras tantas, dignas de nota e reflexão. Durante a trajetória do homem visível, tem-se a necessidade de se agrupar procurando no outro ou outros um modo de sobreviver, reconhecer-se e ser aceito.

Hannah Arendt (1991, p. 14), ao discorrer sobre o homem como ser social ou político, entende que a necessidade de inserir-se ao grupo, não é exclusiva dos homens, mas, também se verifica nos animais:

Não que Aristóteles ou Platão ignorasse ou não desse importância ao fato de que o homem não pode viver fora da companhia dos homens; simplesmente não incluíam tal condição entre as características especificamente humanas. Pelo contrário, ela era algo que a vida humana tinha em comum com a vida animal - razão suficiente para que não pudesse ser fundamentalmente humana. A Companhia natural, meramente social, da espécie humana era vista como limitação imposta pelas necessidades da vida biológica, necessidades estas que são as mesmas para o animal humano e para outras formas de vida animal.

A autora esclarece que, ante essas necessidades, o homem se diferencia pela sua capacidade de organizar-se politicamente, pois “[...] Segundo o pensamento grego, a capacidade humana de organização política não apenas difere mas é diretamente oposta a essa associação natural cujo centro é constituído pela casa (oikia) e pela família" (ARENDT, p. 14).

Inserido nesse pensamento filosófico, surgem referências sobre a família, como o centro da vida privada do indivíduo. Este, dividido entre o público e o privado, o social e o político. Incontestável a dicotomia e a importância desses extremos na vida das sociedades e no desenvolvimento do homem para que possamos compreender como as relações familiares e de parentesco estiveram e estão presentes em muitos dos questionamentos e discussões na seara do direito das famílias.

O direito romano, tomado como base de muitas legislações, é rico nos exemplos sobre relações familiares, sucessões e direitos delas decorrentes, sendo indispensável seu estudo para que se possa compreender o quanto já se caminhou na conquista de igualdade entre o homem e a mulher (poder familiar), entre os filhos (havidos ou não dentro do casamento), e outros. Ao discorrer sobre as famílias romanas, e como se estabeleciam as relações de parentesco, 
ressalta Cassettari (2014, p. 5) que:

Era com efeito, a religião doméstica que constituía o parentesco. Dois homens podiam se dizer parentes se compartilhassem os mesmos deuses, o mesmo fogo doméstico, o mesmo repasto fúnebre. Como o direito de fazer sacrifícios no fogo doméstico e o culto dos mortos somente se transmitiam por via masculina, era impossível que se fosse parente por meio das mulheres, assim o filho pertencia totalmente ao pai.

Tal colocação, à primeira vista, pode causar certa estranheza, todavia, Cassetari (2014, p. 06) esclarece que:

Silvio Meira ensina que o parentesco romano, para efeitos civis, não se baseava nos laços de sangue, mas no poder (potestas). Seriam parentes as pessoas que estivessem sob o poder do mesmo pater, ligadas pelo parentesco masculino. Essas pessoas eram chamadas agnadas e o parentesco daí resultante denominava-se agnatio. O pater e seus descendentes eram agnados entre si, Já o parentesco pelo sangue, com relação à família materna ou paterna, chamava-se cognatio e não produzia efeitos civis. Era um parentesco natural. Essa a diferença profunda entre o parentesco romano antigo e o moderno.

Este salto histórico denota um panorama interessante, pois se no início a sobrevivência era o fator maior de formação dos núcleos familiares, posteriormente, tem-se no contexto romano, a prevalência da religião, do culto aos mesmos deuses e a figura do pai como o centro do qual emana a relação de parentesco e os direitos/ efeitos civis relacionados à sucessão e hereditariedade. O patriarcalismo é a essência das relações familiares romanas e, se houve um abrandamento no decorrer dos séculos, é inegável que em várias culturas e povos, ainda permanece vivo como elemento norteador na formação de núcleos familiares.

Necessário se faz que o estudo ora proposto, primeiramente, adentre as concepções anteriormente atribuídas à família, os conceitos atualmente adotados pela doutrina, bem como a análise dos diversos tipos de famílias consagrados pelo direito pátrio, e àquelas que, embora não previstas pelo direito, são uma realidade no seio da sociedade, para que se possa compreender como as mutações familiares impõem uma atividade judicial (norma) e legislativa (enunciado normativo) que lhes abarque, tornando-as legítimas. 


\section{A FAMÍLIA: NOVAS FORMAS}

A família, antes formada pelos pais e filhos, com o passar do tempo, adotou novos contornos e formatos que, se não correspondem ao formato tradicional, atendem aos anseios daqueles que a integram. Se, anteriormente, a estrutura familiar era proeminentemente patriarcal e resumia-se apenas ao casal e seus descendentes, hoje, a família admite estruturas em muito diferenciadas do modelo tido como o ideal ou correto pela sociedade de 50 ou de 30 anos atrás.

O homem, anteriormente tido como o chefe da família, não era apenas o provedor mas, aquele que detinha o poder de decisão sobre tudo e todos os membros da família que a ele eram subordinados. À mulher cabiam as tarefas domésticas e os cuidados com a prole. Os filhos ficavam submetidos ao poder do patriarca e, em alguns casos, inclusive, a profissão e o casamento eram decididos e acertados pelo pai. A autonomia filial só se verificava com a saída do filho da "casa do pai".

Kehl (2013, p. 167), citando Maria Ângela D’Incao, esclarece acerca dessa dinâmica familiar fechada e austera, desenvolvida desde o século XIX na sociedade burguesa brasileira:

Naquele período, o desenvolvimento das cidades e da vida burguesa influiu também na arquitetura das residências, procurando tornar o convívio familiar mais íntimo, mais aconchegante, o que significa: mais separado do tumulto das ruas e do burburinho da gente do povo. Esta tendência de fechamento da família sobre si mesma foi o início do que D’Incao chama de processo de privatização da família, marcado pela valorização da intimidade.

Ocorre, entretanto que, avanços científicos, econômicos e tecnológicos existentes nas sociedades, fomentaram aos poucos e, reflexamente, a modificação da estrutura familiar. Momento marcante dentro desse contexto é a Revolução Industrial, tida por alguns como divisora de águas dentro das relações familiares. Anterior à Revolução Industrial (iniciada em 1750), à mulher eram conferidos os cuidados com os filhos e com o lar conjugal, mas, com a necessidade crescente de mão de obra nas fábricas inglesas (em um primeiro momento), a mulher viu-se premida a ingressar no mercado de trabalho para fazer frente às despesas da família. Tornou-se membro financeiramente ativo do núcleo familiar, muito embora, ainda, não tenha alcançado a independência necessária ou a almejada igualdade em relação ao marido.

Outras mudanças viriam a fortalecer o surgimento de novos modelos de família, entre elas, o ingresso das mulheres em universidades, o direito ao voto, o 
reconhecimento da igualdade entre homens e mulheres. Ademais, é possível citar alguns avanços legislativos de suma importância à caracterização das novas famílias, entre eles o Estatuto da Mulher Casada (Lei n. ${ }^{\circ}$ 4.121/1962) e a Instituição do Divórcio (EC 9/1977 e Lei n. ${ }^{\circ}$ 6.515/1977). Na Constituição Federal de 1988, a igualdade entre homens e mulheres, a proibição de qualquer tipo de diferenciação ou distinção entre os filhos, em tempo, o reconhecimento da união estável como núcleo familiar equiparado àquele oriundo do casamento e mais recentemente, a EC 66/2010 (divórcio) e o reconhecimento da união estável homoafetiva (ADI 4277/DF e ADPF132/ RJ) pelo Supremo Tribunal Federal.

Para que se tenha uma ideia de como a família, hoje, tem um espectro mais abrangente, basta a simples leitura de algumas definições de família antes esposadas em nossa doutrina, tal como "[...] A família se apresenta, portanto, como instituição que surge e se desenvolve do conúbio entre homem e a mulher e que vai merecer a mais deliberada proteção do Estado que nela vê a célula básica de sua organização" (RODRIGUES, 1987, p.6). Nota-se a limitação e legitimidade da família conferida apenas àquela formada pelo casamento entre homem e mulher.

Hoje, tem-se o conceito da família eudemonista, mais ampla, fundada por laços de afeto e amparada por princípios como o da dignidade da pessoa humana, o da igualdade e respeito à diferença, o da solidariedade entre seus membros, o da proteção integral às crianças, aos adolescentes e aos idosos. Sobre esta amplitude da família atual, leciona Dias (2009, p. 43), para quem:

O novo modelo da família funda-se sobre pilares da repersonalização, da afetividade, da pluralidade e do eudemonismo, impingindo nova roupagem axiológica ao direito de família. Agora, a tônica reside no indivíduo, e não mais nos bens ou coisas que guarnecem a relação familiar. A famíliainstituição foi substituída pela família-instrumento, ou seja, ela existe e contribuí tanto para o desenvolvimento da personalidade de seus integrantes como para o crescimento e formação da própria sociedade, justificando, com isso, a sua proteção pelo Estado.

Não se pode negar que, atualmente, há diferentes formatos de família e, um simples olhar sobre a sociedade brasileira contemporânea, traz, à tona, tais conclusões, pois a doutrina cita como família: a família matrimonial (constituída através do casamento), a família informal (conhecida união estável), família homoafetiva (união estável homoafetiva e, atualmente, pelo casamento homoafetivo), família monoparental (formada por um dos genitores e seus descendentes), família anaparental 
(convivência entre parentes, ou, entre pessoas que, mesmo não sendo parentes, constituem núcleo familiar, por exemplo, ex.: irmãos), família pluriparental, mosaico, ensambladas ou tentaculares (nascidas após o desfazimento de casamentos/uniões anteriores, com a reconstrução de um novo lar/união).

Alguns autores, ainda, citam as famílias paralelas como entidades familiares. Trata-se, entretanto, de campo ainda cercado de controvérsia dentro da doutrina, pois implica, entre outros, em estudos sobre os deveres conjugais e sua violação, o direito da concubina que, segundo Dias, é tema coberto de preconceito e sujeito à invisibilidade. $\mathrm{O}$ fato é que as famílias, mesmo aquelas a que são endereçadas o preconceito e a citada invisibilidade, não deixam de existir por conta destes fatores, ao contrário, necessitam de alguma forma, de reconhecimento e legitimidade, pois, o núcleo familiar, além do afeto que lhe fortalece as bases, é responsável pelo surgimento de uma gama de relações pessoais e patrimoniais que, uma vez estabelecidas, merecem amparo legal.

Um claro exemplo dessas situações, em que a lei se omite, é o trazido nas colocações de Chaves (2011, p. 33), que, ao tratar das uniões homoafetivas, ensina que:

Como já referido, anteriormente, os relacionamentos homoafetivos sempre existiram e, dia após dia, demandam soluções judiciais. Os cientistas, estudiosos e operadores do Direito não podem ficar alheios a este fato social, que em boa parte dos ordenamentos existentes não está juridicamente tutelado. Mais note-se que, via de regra, o fato social antecede a lei.

Exatamente, a questão da importância do fato social, como instrumento fomentador de uma legislação protetiva na seara do Direito de Família é que tem levado doutrinadores (BARROS, 2003, p. 143), estudiosos e operadores do direito a buscarem formas judiciais de, em um primeiro momento, alcançarem o reconhecimento e amparo de arranjos familiares diversos do convencional, por meio da argumentação principiológica, da arguição de violação de direitos humanos e direitos fundamentais. Foi o que ocorreu no julgamento da ADI 4277/DF e ADPF132/RJ pelo Supremo Tribunal Federal que reconheceu a união estável homoafetiva.

Os avanços na seara familiar, embora tímidos, já alçaram conquistas que beneficiaram uma porção significativa de pessoas que optaram por constituírem uma família com base no afeto, embora distinta do tradicional modelo de entidade familiar. Neste sentido, e atenta à importância do afeto no direito das famílias, afirma Maluf (2012, p. 7) que, 
[...] tanto isso é verdade que a formação da família na pós-modernidade possui sua gênese mais fincada no afeto, no amor interpessoal e na valorização da dignidade do ser humano, observadas as peculiaridades que envolvem o ser individualmente considerado.

Talvez, esse novo modo de conceber e compreender as famílias seja a chave para que o legislador pátrio, despido de seus preconceitos e com verdadeira visão humanista, possa dar uma passo além, normatizando, finalmente, as relações familiares que ainda se encontram à margem, mas nem por isso deixam de existir, como é o caso das famílias mosaico ou recompostas que vivenciam a multiparentalidade e, até o presente momento, não têm reconhecida a situação fática pautada pela afetividade.

\section{FAMÍLIA RECOMPOSTA E A MULTIPARENTALIDADE}

Adentrar ao estudo das famílias recompostas impõe que, primeiramente, entenda o que vem a ser o afeto. Para tanto, vem ao encontro a essas aspirações as palavras de Maluf (2012, p. 19), para quem:

A afeição, ligada à vinda do afeto, é representada por um apego a alguém ou alguma coisa, gerando carinho, saudade, confiança ou intimidade. Representa o termo perfeito para representar a ligação especial que existe entre duas pessoas, É, por conseguinte, um dos sentimentos que mais gera autoestima entre pessoas, principalmente as jovens e as idosas, pois induz à produção de oxitocina, hormônio que garante no organismo a sensação de perene bem-estar.

As consequências desencadeadas pelo afeto, como se constata, vão muito além da simples união de seres que se querem bem e optam pela comunhão de vida, construindo um lar e formando uma família. Este bem querer, existente entre os membros de uma família, também lhes confere a segurança de estarem inseridos em um núcleo onde, em tese, haverá solidariedade mútua, respeito, promoção do indivíduo, formação de sua personalidade e aceitação do outro.

Leciona Barros (2003, p. 149), ao tratar do afeto de sua grandeza e importância, não apenas no direito de família, mas das famílias que, a seu ver:

Eis aí como o afeto é o laço não apenas interno (entre os familiares), mas também externo (entre as famílias), capaz de - pondo a humanidade em cada família - compor todas as famílias em uma só humanidade, constituin- 
do quiçá um dia a família humana universal, cujo lar é a aldeia global, cuja base física é o globo terrestre, mas cuja origem sempre será como sempre foi: a família.

É exatamente este sentimento que anima aqueles que se veem como integrantes de uma família recomposta, em que o traço determinante é o recomeço, a segunda chance. A família mosaico, recomposta, ensamblada ou tentacular é aquela cujas pessoas originam-se de uniões ou casamentos anteriormente desfeitos, e buscam refazer suas vidas em novas uniões. Esclarece Santos (2011, p. 230) a respeito desse novo formato familiar, que:

Não raro, as pessoas descasadas unem-se a outras também descasadas, dando origem a um novo núcleo familiar. Não raro, também essas pessoas trazem para a nova união os filhos provenientes de uniões anteriores, os quais estabelecem uma diversidade de relacionamentos com o padrasto, a madrasta e com os filhos destes. A este tipo de agremiação familiar formado por pessoas provenientes de relacionamentos desfeitos e por seus respectivos filhos dá-se o nome de família mosaico ou famílias mosaicas.

Nos lares recompostos se formam relações de afeto entre os companheiros e, muitas vezes, entre um deles e os filhos do outro, não obstante quando o casal já possuía filhos de relações anteriores, e estes passam a conviver sob o mesmo teto, surgindo uma relação de irmandade entre estes filhos. Não é difícil encontrar pessoas que foram criadas por sua madrasta ou padrasto e, concomitantemente, a este convívio, firmaram laços de amizade com os filhos daqueles. Esta socioafetividade, muito comum em nossos dias, acaba por ensejar, naqueles que a experimentam, um sentimento mais amplo de família. Neste arranjo familiar, já não se fala em meus ou seus, mas, em nossos filhos.

Tamanha complexidade da relação familiar estabelecida é tratada por Kehl (2003, p. 168), ao concluir que:

A família tentacular contemporânea, menos endogâmica e mais arejada que a família estável no padrão oitocentista, traz em seu desenho irregular as marcas dos sonhos frustrados, projetos abandonados e retomados, esperanças de felicidade das quais os filhos, se tiverem sorte, continuam a ser portadores. Pois cada filho de um casal separado é a memória viva do momento em que aquele amor fazia sentido, em que aquele par apostou, na falta de um padrão que corresponda às novas composições familiares, 
na construção de um futuro o mais parecido possível com os ideais da família do passado.

Nessa família, seus membros buscam refazer os laços afetivos, por meio da inclusão de todos. O padrasto assume como seus os filhos da companheira, esta participa da criação dos filhos do companheiro, como se pais biológicos fossem. Os filhos interagem entre si com os filhos havidos desta nova união e com os demais membros da família, avós, tios, primos, etc. Pode-se perguntar, então: E os pais biológicos? Qual o papel deles dentro deste contexto? Quando os pais biológicos não são omissos, participam da vida de seus filhos mesmo após a separação do antigo casal, poder-se-á buscar uma convivência harmoniosa com o novo companheiro ou companheira do ex-esposo ou da ex-esposa.

Os problemas surgem quando os pais biológicos tornam-se ausentes e omissos após a separação, deixando ao padrasto ou à madrasta de seus filhos a responsabilidade pela criação destes. Abre-se, portanto, uma lacuna onde a figura paterna/materna biológica é naturalmente substituída pelo padrasto/madrasta que, com desvelo, age como se pai/mãe fora. Neste caso, é natural que a relação socioafetiva, nascida e cultivada pelos envolvidos, tenha de ser protegida e amparada por lei. Se o afeto é um valor jurídico reconhecido, como negar a estas relações socioafetivas o devido reconhecimento?

Há algum tempo, a parentalidade biológica tem deixado de ser preponderante quando concorrente uma relação de parentalidade socioafetiva. Madaleno (2008, p. 117), sobre a questão, posiciona-se no sentido de que, “[...] O parentesco socioafetivo, amparado nos princípios do moderno direito de família, tais como o da dignidade da pessoa humana, o da solidariedade familiar e o da afetividade, prepondera sobre os laços biológicos".

Destarte, Cassettari (2014, p. 28) também defende a prevalência dos vínculos afetivos sobre os biológicos, ao lecionar que:

Dessa forma, quando a família passa a realizar e concretizar a afetividade humana, ela desloca as funções econômicas, política e religiosa para a afetiva, para determinar a repersonalização das relações civis, que valoriza mais o interesse humano do que as relações patrimoniais, em que a pessoa humana está no centro do Direito, no lugar do patrimônio.

São esses os argumentos que embasam nosso pensamento de que as relações consanguíneas são menos importantes na sociedade do que as que possuem origem na afetividade e na convivência familiar, que embasarão a 
constituição do estado de filiação, pela posse do estado de filho.

É por isso que a família moderna é sempre socioafetiva, já que é um grupo social unido pela convivência afetiva, e que transformou o afeto numa categoria jurídica, por ser um fato gerador de efeitos jurídicos.

Assim, compreendidas, as relações firmadas entre os membros de uma família recomposta são um claro exemplo da vivência do afeto, pois, o padrasto ou a madrasta que se dedica a criar os filhos do companheiro ou companheira, educandoos, proporcionando-os condições para sua formação moral e religiosa, suprindo-os as necessidades materiais e amando-os como filhos, não pode ser relegado a um lugar de menor importância na vida deste enteado ou enteada. $\mathrm{O}$ mesmo se diga daqueles enteados que tem como referência paterna ou materna, o padrasto ou madrasta, que acompanharam os passos, por vezes, desde a infância, estando presentes em toda a sua trajetória de vida.

O Direito das Famílias vem se debruçando sobre casos, cada dia mais comuns, de multiparentalidade em famílias tentaculares. Há, assim como não poderia deixar de ser, aqueles que reputam impossível o reconhecimento desta parentalidade socioafetiva em existindo pais biológicos. Para estes, os vínculos biológicos devem prevalecer, muito embora o movimento jurisprudencial seja em razão contrária a esta posição, além de afirmarem que as questões patrimoniais, leiam-se sucessórias e previdenciárias, seriam por demais complexas com a admissão da multiparentalidade.

As questões sucessórias deverão ser levadas em consideração, com certeza, mas não deverão servir de entrave ao reconhecimento da multiparentalidade, quando a parentalidade socioafetiva se tornou mais presente do que a biológica. $\mathrm{O}$ ideal é que ambas coexistam e não que se sobreponham. Sobre a questão, Cassettari (2014, p. 168) alerta para a necessidade do exame caso a caso, assim:

[...] Essa questão da coexistência de ambas as parentalidades é de suma importância, pois, senão, abriremos a porta para as injustiças e para as pessoas se aproveitarem da evolução doutrinária e jurisprudencial, que fez do Brasil um dos países mais avançados nesse assunto, para que ela seja usada de maneira equivocada.

De fato, a questão não é de fácil resolução, entretanto, necessita de atenção e de respostas, seja do judiciário seja do legislativo, para que não se cometam graves injustiças contra aqueles que conviveram como pais e filhos, criaram laços afetivos e formaram uma família. O silêncio sobre o tema apenas exclui e deixa ao abandono 
estes filhos de afeto e seus pais afetivos, por isso, a importância do direito pressuposto e do direito posto, como um caminho à solução do impasse oriundo das relações estabelecidas nas famílias recompostas.

\section{DIREITO POSTO, DIREITO PRESSUPOSTO E MULTIPARENTALIDADE}

Primeiramente, cabe esclarecer que o presente tópico será desenvolvido tendo como referência, parte da obra intitulada "O Direito Posto e o Direito Pressuposto", de Eros Grau, conforme proposto anteriormente, neste trabalho.

Um primeiro pensamento acerca do direito leva à instantânea menção de ser ele uma forma ou um instrumento de solução de conflitos, isto porque o direito, quando compreendido como um corpo de enunciados normativos, visa regular a conduta dentro de uma determinada sociedade, bem como limitar a liberdade de seus indivíduos em função ou para o bem da coletividade. Utilizando as lições de Grau (2011, p.25), pode-se compreender que:

[...] Assim, o direito pretende proteger e assegurar a liberdade de agir do indivíduo, subordinando-o ao interesse coletivo; ele demarca as áreas da liberdade e do interesse coletivo, tendendo à determinação de um ponto de equilíbrio entre esses dois valores.

Entretanto, tem-se de ter em mente que o direito deriva do fato social, e é uma construção com base nos hábitos, costumes, uma consciência coletiva do que deve ou não ser feito. Emerge em cada sociedade de maneira única, pois cada povo é um, vivenciando uma determinada realidade social, econômica, política e histórica. Estes fatores diferenciam o direito existente em uma e em outra sociedade (GRAU, 2011).

À guisa de reflexão, é necessário entrever o direito não como algo externo à sociedade, mas como uma de suas faces internas, no sentido de que, tal como afirma Grau (2011, p. 73) inspirado em Duguit, ao tratar do direito pressuposto, possa se compreender que:

O que transforma uma norma social em norma jurídica é o fato de a massa das consciências individuais chegar à compreensão de que a sansão material desta norma pode ser socialmente organizada - isto é que a reação social contra sua violação pode ser socialmente organizada pelo emprego da coerção. 
Interessante perceber que o direito, em sua origem, transcende aos processos legislativos, pois deve ser animado por uma anterior consciência social acerca de suas razões de ser, não obstante, ainda não ser objeto de um enunciado normativo. $O$ direito pressuposto é criado pelo povo, cabendo ao Estado a criação do direito posto ${ }^{1}$.

Se ao Estado incumbe a criação do direito posto, criando o enunciado normativo, nada mais coerente de que fosse este direito um reflexo das aspirações sociais, na busca de harmonização entre o que anseia a sociedade e o que é imposto pelo Estado. Todavia, isto nem sempre se verifica, e diversos são os motivos deste distanciamento entre o desejo de um povo e o que é normatizado pelo Estado. Neste ponto, residem as questões relacionadas à legitimidade do direito, afirmando Grau (2011, p. 86) que "[...] dotado de legitimidade é o direito posto que corresponde ao direito pressuposto."

Interessa, pois, a transposição desses conceitos às questões atinentes ao reconhecimento e à admissibilidade da multiparentalidade. Quando da exposição sobre as famílias recompostas e as relações afetivas estabelecidas entre padrastos e/ ou madrastas e seus enteados gerando uma relação de socioafetividade, embora preexistente o vínculo biológico com os genitores, restou clara a complexidade do tema por tratar-se de algo novo e pelo confronto que, à primeira vista, parece surgir entre a parentalidade socioafetiva versus parentalidade biológica.

Muito embora essa possa ser a primeira impressão trazida pelo tema, a mesma não condiz com a extensão real da situação familiar em estudo. A multiparentalidade não visa a exclusão ou prevalência de um vínculo afetivo sobre o biológico, ou vice e versa, mas, e ao contrário, propõe a coexistência dos vínculos harmoniosamente em favor dos interesses dos enteados e padrastos/madrastas que criaram uma relação de afeto para além do madrastio/padrastio e, em muito semelhante, as relações paterno-filiais.

Admite-se, no Direito das Famílias, o afeto como elemento essencial nas relações. Admite-se, também, que as novas formas de família merecem respeito e amparo legal, a fim de proteger o núcleo familiar e seus membros. Não se nega a importância de princípios como o da dignidade da pessoa humana ou da igualdade, ou, ainda, do melhor interesse da criança e do adolescente como norteadores do direito das famílias. Assim, como negar a existência da multiparentalidade? E nos casos em

\footnotetext{
${ }^{1}$ Ao tratar deste aspecto Grau é muito claro em suas colocações, pois para o autor: “[...] O povo - digo - produz o direito pressuposto; o Estado produz o direito posto, que conhecemos como direito moderno ou direito formal; apenas o direito produzido pelo povo é comprometido com a justiça (GRAU, 2011, p. 25).
} 
que o reconhecimento da multiparentalidade é pleiteado em juízo? Se, na sociedade pós-moderna, a multiparentalidade é fato social aceito sem maiores problemas, o que falta para o Estado transformar o direito pressuposto em um direito posto?

Ante essas indagações, faz-se coro com os ensinamentos do autor em epígrafe, ao afirmar que,

[...] o direito posto não legitima o interesse e as aspirações sociais; as aspirações sociais e o interesse social é que legitimam o direito (= direito posto). Isto importa lembrarmos Von Ihering [1884/424]: 'O direito existe em função da sociedade; não a sociedade em função do direito' (GRAU, 2011, p.87).

O impasse criado pela existência da multiparentalidade de fato tem levado as partes envolvidas às portas dos Tribunais em busca do almejado reconhecimento. Um desses casos ocorreu no Rio Grande do Sul, na Comarca de São Francisco de Assis, onde duas crianças de dois e sete anos de idade foram criadas pela madrasta, segunda esposa do pai, e com ela estabeleceram relação socioafetiva. $\mathrm{O}$ caso foi prestigiado como um avanço, pelo professor Flávio Tartuce (2015, p. 01), conforme segue:

A vara Judicial da Comarca de São Francisco de Assis/RS reconheceu a possibilidade de duas crianças terem seus registros civis alterados, para a inclusão de segunda mãe nas certidões. A madrasta e as crianças ajuizaram ação declaratória de maternidade socioafetiva, entretanto, sem excluir o nome da mãe biológica do registro.

$[\ldots]$

Em sua decisão, a juíza de Direito Carine Labres, substituta da vara, dispôs que 'as relações de afeto têm desafiado os legisladores que, muitas vezes arraigados ao preconceito, ao termo de críticas que maculam a imagem daqueles que almejam a reeleição, silenciam face à realidade que lhes salta aos olhos.

$\mathrm{O}$ fato de o ordenamento jurídico não prever a possibilidade da dupla maternidade não pode significar impossibilidade jurídica do pedido. Afinal, não são os fatos que se amoldam às leis, mas sim estas são criadas para regular as consequências que advém dos fatos, objetivando a manter a ordem pública e a paz social', conclui a juíza.

A última colocação da magistrada, pontuando sobre a necessidade das leis serem criadas em função dos fatos, da realidade social que não é estanque e não o in- 
verso, demonstra a preocupação de alguns magistrados que, devido a uma omissão legislativa, têm de "resolver o conflito", fundamentando a norma em princípios constitucionais, na melhor doutrina, bem como em consonância com a realidade social. A fala da magistrada vem ao encontro dos ensinamentos de Von Ihering: "O direito existe em função da sociedade; não a sociedade em função do direito" (GRAU, 2011, p. 87).

A multiparentalidade surge, exatamente, nessa lacuna existente entre o fato social e a inexistência de enunciado normativo que a regule. Ou melhor, a multiparentalidade vivenciada de fato por muitas famílias recompostas seria um direito pressuposto, pois, emerge das relações familiares e se manifesta dentro das relações sociais, mas não está prevista em lei, não recebe guarida ou amparo do direito posto, buscando por este motivo, no poder judiciário, reconhecimento e proteção.

A atividade jurisdicional poderia, inclusive, ser questionada por aqueles positivistas extremados, no sentido de entenderem-na confrontada ao nosso objeto de estudo, como uma forma de ativismo judicial. Entretanto, seria possível rebater tais críticas se entendido que, em sua atividade, os juízes têm de interpretar textos normativos produzindo a norma, ou melhor, “[...] é função dos juízes a de produzir direito formal, ainda que possam, na medida em que criam normas, produzir direito não formal"(GRAU, 2011, p. 94)

Não poderá o judiciário furtar-se de apreciar questões sobre multiparentalidade todas as vezes que para isto for chamado. Ao contrário, deverá, como a brava magistrada, enfrentar o tema com destemor e com sensibilidade suficiente para adequar a norma aos fatos.

\section{CONSIDERAÇÕES FINAIS}

A família, ao contrário do que os críticos mais conservadores e pessimistas dizem, não tem passado por uma crise, mas sim, tem se transformado, se reformulado e se reinventado ante as mudanças que a sociedade global tem enfrentado. Hoje, considerando a tecnologia, a globalização, a facilidade dos meios de comunicação e o trânsito entre países maior do que há alguns anos, tais fatores, somados às questões culturais, sociais, econômicas e políticas, têm se refletido na constituição das novas famílias.

O que não se modificou foi a vontade do indivíduo de partilhar sua vida com o outro. Ser aceito, acolhido e respeitado ainda faz parte das necessidades básicas do ser humano, tais como amar e ser amado. O afeto, este laço que une os membros de uma família, sempre existiu, mas hoje é um valor jurídico que se sobrepõe, inclusive, às questões biológicas. 
Ao falar a respeito das famílias recompostas, imprescindível entender que, na dinâmica desse núcleo familiar, os papéis de pai e mãe, por vezes, são desempenhados pelos padrastos e madrastas, com dedicação, cuidado, carinho, afeto e amor. Os filhos do companheiro ou da companheira são aceitos pelo outro como se fossem seus. Os filhos de ambos os companheiros convivem como irmãos e neste ambiente familiar plural são bem vindos os filhos havidos pelo casal, que virão se juntar aos demais.

Durante uma participação em Congresso, "conheci um casal que formou uma família recomposta e vivenciava há 20 anos a multiparentalidade. Na ocasião, para minha grata surpresa, senti em ambos o desejo de que este reconhecimento fosse normatizado por meio de uma legislação, pois ante a ausência de um enunciado normativo, pretendiam ingressar em juízo para verem reconhecidos os filhos socioafetivos de ambos".

A multiparentalidade é uma realidade, sempre foi e continuará sendo. Ocorre que, atualmente, com a valorização das relações socioafetivas, estas famílias desejam sua inclusão legal, pois a sociedade não se opõem a elas. Cabe ao legislador deixar de se omitir sobre o assunto, pois, se não o fizer, ao judiciário não será dada a oportunidade de eximir-se de um pronunciamento sobre o tema. É hora de o Estado legitimar o direito posto, fazendo-o corresponder aos anseios da sociedade, ao direito pressuposto, do povo e das famílias recompostas.

\section{REFERÊNCIAS}

ARENDT, Hannah. A condição humana. 4. ed. São Paulo: Nova Cultual, 1991.

BARROS, Sérgio Resende de. Direitos humanos da família: dos fundamentais aos operacionais. In: GROENINGA, Giselle Câmara; PEREIRA, Rodrigo da Cunha. Direito de família e psicanálise: rumo a uma nova epistemologia. 1. ed. Rio de Janeiro: Imago Editora, 2003.

CASSETTARI, Christiano. Multiparentalidade e parentalidade socioafetiva. 1. ed. São Paulo: Editora Atlas, 2014.

CHAVES, Mariana. Homoafetividade e direito: proteção constitucional, uniões, casamento e parentalidade - um panorama luso-brasileiro. 1. ed. Curitiba: Juruá, 2011. 
DIAS, Maria Berenice. Manual de direito das famílias. 5. ed. São Paulo: Revista dos Tribunais, 2009.

GRAU, Eros. O Direito posto e o direito pressuposto. 8. ed. São Paulo: Malheiros, 2011.

KEHL, Maria Rita. Em defesa da família tentacular. In: GROENINGA, Giselle Câmara; PEREIRA, Rodrigo da Cunha. Direito de família e psicanálise: rumo a uma nova epistemologia. 1. ed. Rio de Janeiro: Imago Editora, 2003.

MADALENO, Rolf. Filiação sucessória: parentalidade socioafetiva e biológica. Revista Brasileira de Direito das Famílias e das Sucessões, Porto Alegre, n. ${ }^{\circ}$ 6, Editora Magister, 2008.

MALUF, Adriana Caldas do Rego Freitas Dabus. Direito das famílias: amor e bioética. 1. ed. Rio de Janeiro: Elsevier, 2012.

RODRIGUES, Silvio. Direito civil. Direito de família. 13. ed. São Paulo: Saraiva, 1987. v. VI.

SANTOS, Romualdo Baptista. A tutela jurídica da afetividade. 1. ed. Curitiba: Juruá. 2011.

TARTUCE, Flávio. Maternidade socioafetiva. Disponível em: $<$ http://professorflaviotartuce. blogspot.com.br/2013/08/mais-uma-sentenca-reconhece.html>. Acesso em: 08 fev. 2015. 